\title{
Cross-Instrument Division of Labor in International ODA: Grant-loan Allocation and Implications for Korean $\mathrm{ODA}^{*}$
}

\author{
MIKYUNG YUN ${ }^{* *}$
}

The importance of the division of labor to enhance donor coordination is increasingly recognized, but little attention has been paid to the cross-instrument division of labor, such as grant-loan coordination. This paper analyses the current international division of labor that has emerged between grant and loan aid and elicits implications for emerging donors such as the Republic of Korea. This paper argues that considering the international division of labor and characteristics of Korean ODA, Korea should strengthen cooperation with multilateral donors and that its coordination strategies with bilateral donors should depend on whether they are grant oriented or loan oriented.

Keywords: Aid Effectiveness, Aid Harmonization and Coordination, Division of Labor in ODA, Grant-Loan Aid Allocation, Emerging Donor

This study builds on materials from the "Balanced Development of Grant and Loan Aid through Coordination (in Korean)," a prior research project commissioned by the EXIM Bank of Korea in 2009. Korea in this paper refers to the Republic of Korea.

Associate Professor, School of International Studies, the Catholic University of Korea 


\section{INTRODUCTION}

$\mathrm{M}$ ost of the world's official development aid comes from the member countries of the Development Aid Committee (DAC) of the OECD. In 2009 alone, total ODA by DAC countries recorded about 120 billion dollars, which is more than a 100\% increase from the 2005 level (OECD DAC Database). However, ODA from non-DAC countries has also been on the rise. Their contribution is estimated to be around $7.8-9.8 \%$ of total international ODA in 2006 and around 9-10\% in 2008 (Smith et al. 2010). In addition, the importance of private aid has also increased. Roughly US\$49.1 billion in private donations and non-governmental program funding flowed to developing countries in 2007, compared to US\$103 billion in ODA (Utz 2010, 6). Indeed, aid donors and agencies have proliferated over the years, resulting in a great deal of duplication and increasing costs of aid administration. As of 2008 , there were over 100 ODA agencies. In addition to official aid agencies, there were more than 35,000 NGOs providing humanitarian aid registered with the UN. This number is expected to have increased by now. On average, one recipient gets aid from 26 donor countries. Only $13 \%$ of recipients have less than 9 donor countries, while $25 \%$ has more than 30 donor countries (Riddell 2008). According to one telling testimony, there were " 25 bilateral and 19 multilateral donors and about 350 international NGOs operating in Vietnam, accounting for over 8,000 development projects" (Knack and Rahman 2008, 334).

This has led to calls for greater donor harmonization and coordination, which have become important elements of the Paris Declaration of 2005 (PD) and the Accra Action Agenda (AAA) of 2008. Coordination among the many donors with varying motivations is a daunting problem, and it poses special challenges to emerging donors such as Korea, with an increasing but still relatively small size of aid. How should countries such as Korea, relatively new on the ODA scene, allocate its expanding aid resources, without adding to yet greater fragmentation and proliferation? What should be its role in the international division of labor in ODA? What strategies can guide its cooperation with other donors?

As a preparatory step towards addressing these issues, this paper examines the current division of labor in international ODA, with a focus on grant-loan allocation. It basically documents how grant and loan aid are currently allocated across regions, levels of recipient income and aid sectors. As such, this paper is largely empirical than theoretical, and the empirics involved are simple attempts to derive insights regarding the general direction Korea might follow in its efforts at donor coordination, rather than to systematically prove any given hypothesis. However, the paper draws broadly from the relevant literature on the division of labor in ODA. The focus of the paper on grant-loan allocation is due to the relatively low grant ratio of Korea, especially for low income countries, ${ }^{1}$ and the recent efforts to strengthen cooperation between the two 
official agencies, the Korea International Cooperation Agency (KOICA) and the Export-Import Bank of Korea, which specialize in providing grant and loan aid respectively. This paper therefore contributes to the growing policy literature on the division of labor in ODA which has not yet seen much analysis of cross-modalities or instruments division of labor such as grant-loan coordination.

The next section provides an overview of the relevant literature, placing this study in the general literature on the division of labor (DoL) in aid, and explaining the methodology of this paper. Section III first compares the overall allocation behavior of bilateral donors and multilateral donors across region and income level of recipients. Section IV provides a more complete account of the division of labor between grant and loan aid, including the allocation pattern by modality and sector. Section V examines the trends in ROK's ODA and suggests strategies for international cooperation. The last section concludes by way of providing a summary.

\section{LITERATURE REVIEW AND METHODOLOGY}

The harms done by excessive fragmentation are well documented in the literature. The damages range from simple wasting of resources due to duplicative and contradictory bureaucratic procedures to more lasting damages such as the erosion of recipient country's administrative capacity and increased corruption with negative consequences on economic growth (Knack and Rhaman 2008: Djankov et al. 2009).

While greater donor coordination is expected to mitigate the problems of fragmentation, this does not come without costs. Donor concentration can cause inefficient disbursement behavior, and collusion enables donors to avoid individual responsibility, thus lowering donor accountability (Frot and Santiso 2009; Easterly 2003). Moreover, greater coordination may increase coordination costs for some parties such as lead donors, while reducing visibility of delegating donors. All of this may negatively affect overall incentives to provide aid. Moreover, donor concentration is not always welcomed by recipients. Recipients sometimes appreciate small donors because of their flexibility and are more sensitive to modalities of aid disbursement (e.g., preference for general budget support), rather than the number of donors they have to deal with (Dreher and Michaelowa 2010).

It is not obvious, then, what the optimal level of donor division of labor is. What is clear is that the relationship between fragmentation and effectiveness of aid is not linear. For example, Kimura et al. (2007) find that the relationship between fragmentation and aid effectiveness has an inverted- $U$ shape. The interpretation is that aid proliferation hinders growth due to high transaction costs but then after a threshold, as aid becomes concentrated, growth is again hindered due to less competition among donors. Further, as Dreher and Michaelowa (2010) 
notes, the optimum level of fragmentation, or degree of the division of labor among donors, may vary depending on the modalities of aid disbursement, the particular sector concerned, and specific country characteristics.

While studies on aid fragmentation mostly focus on the problems of congestion externality within a single recipient country, another body of normative literature argues that optimal aid allocation is possible, at least across countries. Utz (2010) gives a concise review of this literature, classifying it into three approaches: needs-based, poverty-efficiency, and equal-opportunity approaches. The proponents of the needs based approach argue that aid should go to the neediest places, with low per capita income, poverty, life expectancy, literacy and financing gaps. Unlike the needs-based approach which does not pay attention to possibly different marginal cost of aid in reducing poverty among recipients, this is the most important consideration in the "poverty-efficiency" approach. Based on the premise that aid is only effective when there are good policies in place, and that aid's effect on growth is characterized by diminishing returns, Collier and Dollar (2001) argue that redistributing aid to countries with the most poverty and best policies will lead to halving the number of the world's poor people.? On the other hand, the equal-opportunity approach secks to establish equal opportunity to achieve a desired outcome such as economic growth and poverty reduction. Aid should remove structural disadvantages, equalizing risks in reducing poverty. One way of doing this is to give more to the poorest because this equalizes poverty risks better than other methods, while decreasing global poverty in the sense of the poverty efficiency approach.

Noting the absence of any consensus on what the optimal allocation rule is, Utz (2010) uses four different benchmarks (egalitarian allocation in which each country receives the same amount, average donor behavior, poverty-efficient allocation and IDA's performance based allocation formula) in an attempt to identify countries receiving insufficient aid (i.e., less than the purported "optimal" defined by the benchmarks). The study finds that the answer depends significantly on which benchmark is used, bilateral aid has greater tendency to leave individual countries with insufficient aid than multilateral aid, and that in many cases, underfunding by one source is compensated for by another source. Importantly, the study finds that fragile states are not necessarily more likely to receive less aid.

The optimal allocation rule implicitly assumes that donor provisions will be coordinated. For, otherwise, each donor acting separately to provide to the neediest or to the most poverty efficient may result in herding, and in fact create aid orphans rather than prevent it. However, empirical studies of how donors actually make allocation decisions would make one skeptical of extensive donor coordination across countries. Donors have a mix of different political, commercial and humanitarian motivations. Historical ties, geographic proximity, and domestic politics within donor countries also play a role. In one of the more recent "which-do- 
nor-goes-where" studies, Hoeffler and Outram (2008) show that $50 \%$ of aid is explained by donor-specific effects such as colonial history and geopolitical ties. The remaining $50 \%$ is explained by recipient need $(36 \%)$, donor self interest $(16 \%)$ and recipient merit such as growth, democracy and human rights $(2 \%)$. It is easy to see that aligning the numerous varying motivations among donors will be very strenuous. The international division of labor across countries needs to be approached cautiously not only because it may run against the motivations of specific donors in specific countries but because it may entail "redistribution" of aid among countries.

Coordination within countries to mitigate the problems of fragmentation have progressed the most among EU member countries, through the adoption of the "Code of Conduct on Complementarity and Division of Labor" in 2007. At the operational level, division of labor is achieved through limiting the number of donors per sector, limiting the number of sectors per donor, and delegated cooperation. Under delegated cooperation, the "lead donors" coordinate sector programs with the recipient government and "active donors" participate in policy dialogue and administer own sector activities, while "delegating donors" remain in the background, supporting the program silently through financial contributions. A good example of such delegated cooperation is Sweden's delegation of country programming to Norway in Malawi. Another instrument of coordination already put to use is the Joint Assistance Strategies (JAS), initiated by a number of donors since 2004. Some donors such as the World Bank, Germany and the UK have adopted JAS as the official strategy document, replacing their own format for country strategy papers. The Joint Assistance Strategy has replaced Country Strategy Papers in Uganda and Tanzania. More countries are under preparation to adopt JAS. Evidently, this kind of international coordination requires a system of objective assessment regarding comparative advantage of each donor by both the giving and receiving ends (Murle 2007).

The division of labor literature discussed above pays little attention to grant-loan coordination, which is the focus of this paper. Most studies on grant-loan allocation have been on the differential effects of the two aid instruments on economic growth. ${ }^{3}$ Arguably, one should increase the levels of the instrument that is more effective for economic growth or poverty reduction. The ensuing debate since the controversial Meltzer Report (2000) provoking strong skepticism against loan aid has shown that both grants and loans have their respective roles. Appropriate coordination between the two instruments of aid delivery rather than the substitution of one for the other would be more important. In a recent study, Iimi and Ojima (2008) have shown that it is the combination of grant and loans that maximize growth, and that the level of concessionality may matter more for growth than the size of the loans.

The literature that has greater bearing on grant-loan allocation decision is the international public goods literature. International public goods tend to be 
undersupplied because a country has little incentive to borrow in order to invest in international public goods, when consequent benefits mostly spill over to other countries. In this case, grant-aid may persuade countries to produce more of the international public goods. On the other hand, countries would be more willing to borrow to invest in national public goods, benefits from which would mostly remain within their own respective territories. In this case, it would be more appropriate to finance the project with loan aid with less dangers of moral hazard and burden of conditionality (Mascarenhas and Sandler 2005; Ferroni and Mody 2002). The most efficient financing instrument to finance international public goods therefore, would be a grant-loan package with the proportion of each varying depending on the extent of gains the recipient gets from the public good. Mascarenhas and Sandler (2005) compare the grant-loan allocation behavior of bilateral, multilateral and regional institutions and find that bilateral donors followed the most desirable grant-loan allocation pattern in financing public goods, while regional institutions showed the least desirable pattern, showing no sensitivity to the international versus national aspects of public goods.

The international public goods literature is confined to a small, though growing, realm of aid-financing. Accounts of the cross-instrument division of labor is scanty in comparison to the measuring and monitoring of aid fragmentation, policy suggestions of in-country aid rationalization and mechanisms of coordination, and optimal cross-country allocations of aid. This paper seeks to fill this gap in the literature by mapping the status quo in the current division of labor in grant-loan aid allocation.

Given that various previous studies show that bilateral (primarily grant oriented) and multilateral donors (primarily loan oriented) have different motivations and allocation behavior, the current paper examines bilateral and multilateral donor allocation behavior by comparing their overall and grant-loan allocation patterns by regions and income levels of recipients. This analysis is done mainly relying on the OECD DAC data. Grant-loan allocation is measured by the grant to total aid ratio. Gross disbursement rather than net disbursement is used because the latter tends to inflate grant ratios by reducing the amount of loan aid when principal and interest payments are taken into account.

Grant-loan allocation is difficult to track down by modalities and sector through a bilateral versus multilateral donor comparison using the OECD DAC data since sectoral contribution of multilateral aid is not reported. To explore grant-loan divisions of labor across modalities and sectors, allocation patterns of two groups of bilateral donors, the grant oriented group and the loan oriented group, are compared. The two groups are determined on the basis of changes in the grant-allocation behavior of the donor from 1980 to 2008. Of the 23 DAC member countries, those that have a policy of giving primarily $100 \%$ grants are Ireland, Greece, Luxemburg, New Zealand and Australia. Their average grant ratios 
for the period $1980-2008$ are $100 \%, 99.97 \%$ and $99.91 \%$, respectively. Although not as high as these countries, Nordic countries such as Sweden, Switzerland and Norway also provide predominantly grant aid, with period average grant ratios of $99.36 \%, 99.81 \%$ and $98.36 \%$, respectively. On the other hand, DAC members whose period average grant ratios that fall below $80 \%$ are France $(76.3 \%)$, Germany $(69.98 \%)$, Austria $(71.99 \%)$, Japan $(42.01 \%)$, Korea $(56.86 \%)$, Italy $(72.80 \%)$ and Spain $(62.71 \%)$. These countries are grouped together as loan oriented donors. Other members which do not fall into either group have grant ratios that fall somewhere between around $80 \%$ and around $90 \%$ levels. Although this middle group includes major donors such as the UK and the US, in the following only the two extreme groups are compared to see if donors specialize in different modalities and sectors of aid depending on their grant-loan orientation. The sectoral comparison uses commitment data, since this is the most readily available form of aid data compiled by sector. Although commitment values may differ from the actual amount of aid, it is possible to impute donor's policy towards sectoral allocation by looking at aid commitments.

\section{INTERNATIONAL DIVISION OF LABOR IN ODA BETWEEN BILATERAL AND MULTILATERAL DONORS}

\section{Oterall Allocation Patterns by Region and Income Levels}

Until 2004, the top receiving region of bilateral ODA was Africa. After 2005, attention has changed towards Asia. The level of bilateral aid flowing to developing countries in the Americas consistently takes up around $10 \%$ of total ODA during the whole period of 1980-2008. Oceania has received very little bilateral aid historically, and is showing a further declining trend since 2000. On the other hand, bilateral ODA towards Europe increased in the $2000 \mathrm{~s}$, but is now showing a declining trend (see Figure la and Figure lb).

Multilateral aid has consistently focused on Africa, which received $46.08 \%$ of total multilateral aid in 2008. The second priority region for multilateral aid is Asia, with an allocation of $30.96 \%$. The Americas and Europe are the next important aid destinations for multilateral aid. Aid to Africa surged during 2005-2006, contracting aid resources available to other regions. 2005 was a special year. The OECD/DAC High Level Forum and the Gleneagles G8 meeting, the UN MDG evaluation forum had all taken place then to discuss expanding ODA size. In particular, the commitment by a number of donors leading up to the 2005 Gleneagles G8 meeting to reach the ODA to GNI ratio of $0.7 \%$ by 2015 and to double their aid to Africa, as well as commitment by multilateral financial institutions to undertake debt relief helped to rapidly channel greater amounts of aid to Africa. At the same time, while aid to Asia is showing an 
increasing trend, it seems to be decreasing for the Americas.

Figlire 1. Trends in ODA Allocation by Recipient Region

(a) Bilateral Aid

Unit: \%

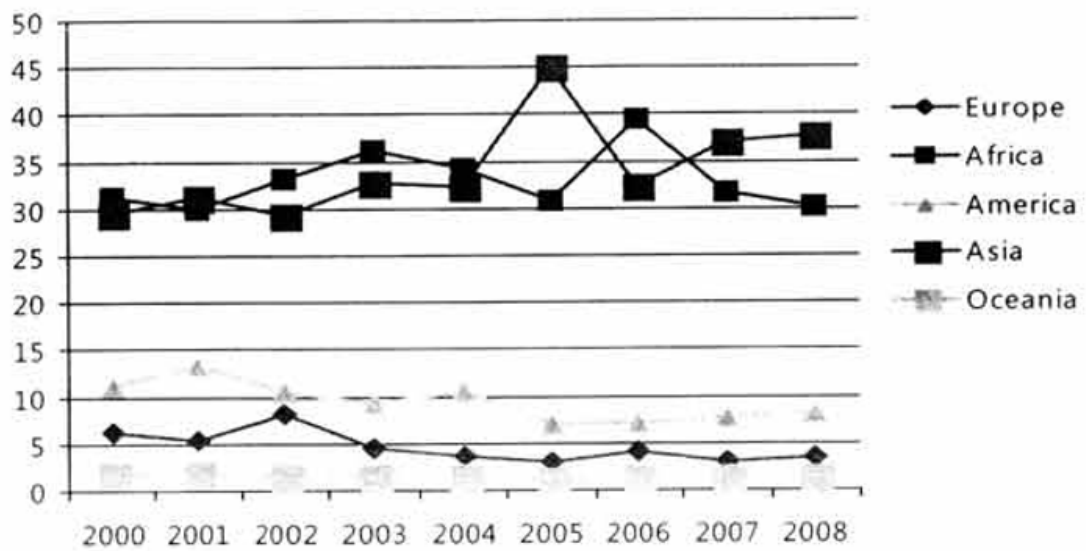

(b) Multilateral Aid

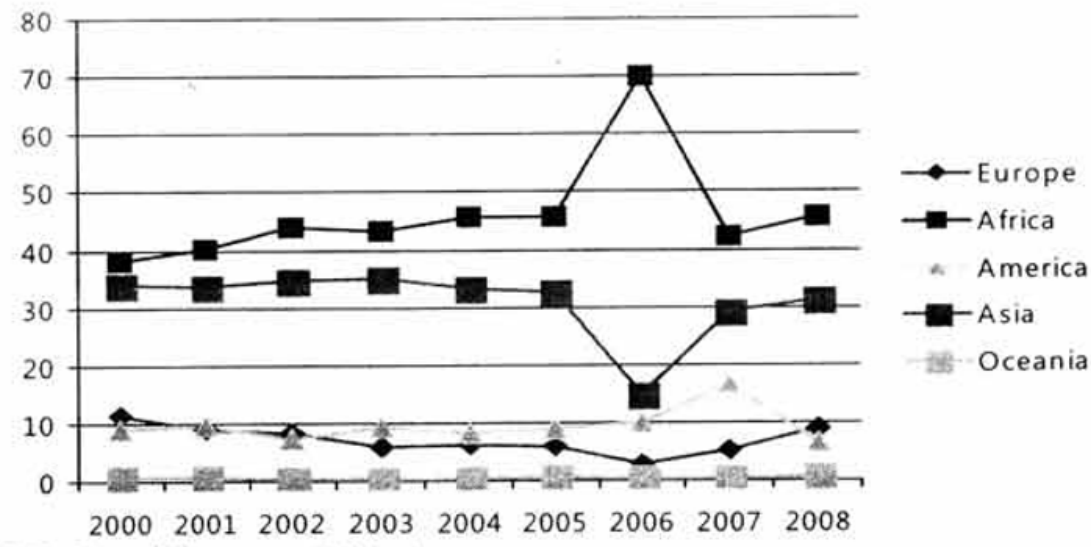

NOTE: Gross disbursement, 2008 prices.

SOURCE: Based on data from OECD DAC.

Bilateral aid is generally concentrated in the lower middle income countries during 2000-2008. This is a matter of concern, especially because when aid to middle income countries increases, there is a simultaneous decrease in aid to least developed countries. At the same time, allocation of aid to other low income countries is even much lower than that of least developed countries, 
falling below $10 \%$ for most of the same period. Aid allocation to high middle income countries rapidly expanded in 2002, but then quickly shrunk, giving an overall period average of $5-10 \%$ (see Figure 2a and Figure 2b).

\section{Figure 2. Trendos in ODA Allocation by Recipient InCOME Levels}

(a) Bilateral Aid

Unit: $\%$
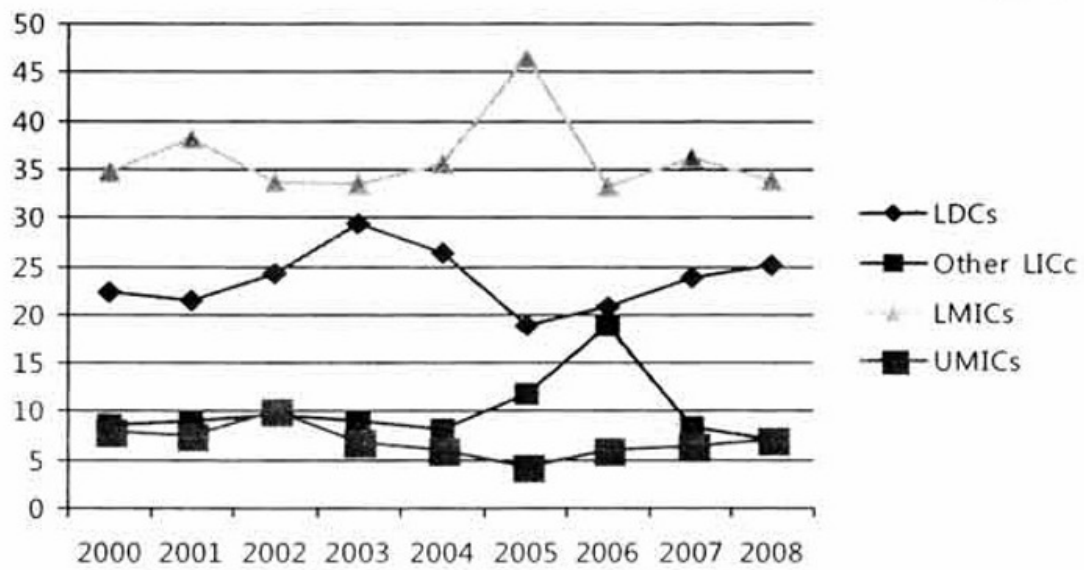

(b) Multilateral Aid

Unit: \%

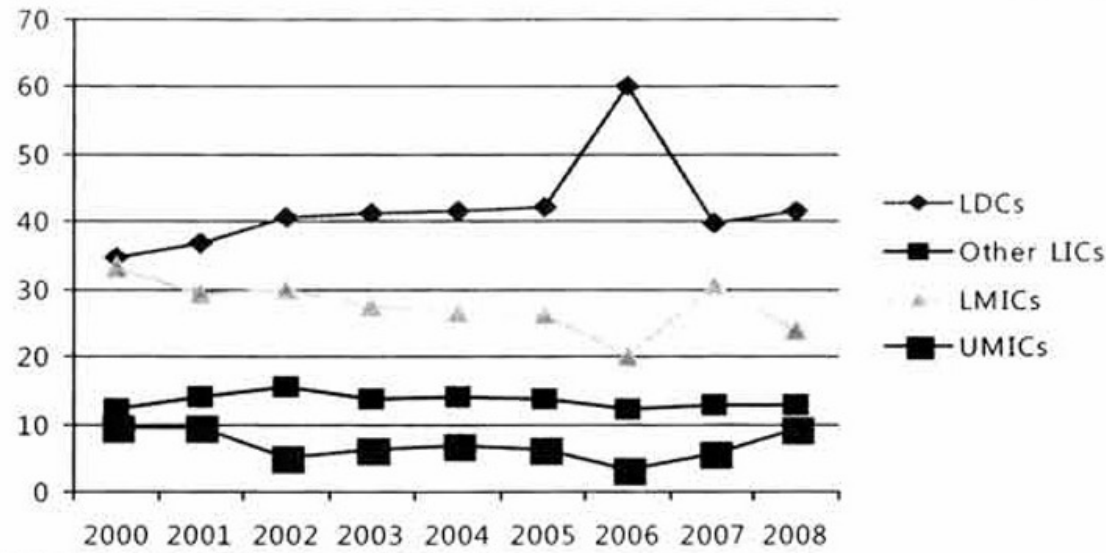

NOTE: a. Gross disbursement, 2008 prices.

b. The OECD DAC classifies recipients into four income groups: least developed countries following the UN definition, other low income countries (countries other than the least developed countries with per capita GNI less than \$935), lower middle income countries (per capita GNI between \$936-\$3,705), and upper middle income countries (per capita GNI between $\$ 83,706-\$ 11,455)$. The thresholds are income levels in 2007 .

SOURCE: Based on data from OECD DAC. 
The regional substitution between least developed countries and middle income countries is repeated in multilateral aid. Fortunately, greater multilateral aid is allocated to least developed countries than to lower middle income countries, reminiscent of Utz (2010)'s finding that underfunding is often compensated by funding from other sources. Nevertheless, even multilateral aid allocates more to lower middle income countries than to other low income countries. Allocation of multilateral aid to other low income countries remained at $12-14 \%$ during the $2000 \mathrm{~s}$, in stark contrast to the rapid increase of bilateral aid to this region during 2004-2007. Allocation to high middle income countries forms less than $10 \%$ of total multilateral aid, but is showing an increasing trend recently. Multilateral aid allocates $30-50 \%$ of the total to heavily indebted poor countries. ${ }^{4}$

\section{Division of labor between bilateral and multilateral aid}

The above discussion shows that the regional coverage of bilateral aid is more widespread and more volatile over time than multilateral aid, with priority switching from region to region at different times. Multilateral aid, on the other hand, has more consistently focused on Africa, the poorest continent. At the same time, the income group of countries benefiting the most from bilateral aid was the lower middle income group, whereas the greatest beneficiary of multilateral aid was least developed countries rather than lower middle income countries. There thus seems to be clear differences between bilateral and multilateral aid allocation behavior, so as to give rise to a natural division of labor between the two types of donors. While bilateral aid focuses on the lower middle income group but is more geographically widespread, multilateral aid focuses on the least developed countries and concentrates mostly on Africa. This difference in the allocation pattern between bilateral and multilateral aid is reflective of the discussion in Section II. While bilateral aid tends to have a more complex mix of varying motivations, multilateral aid may be more coordinated, with allocation rule based more firmly on needs and policy performance.

\section{INTERNATIONAL DIVISION OF LABOR IN ODA BETWEEN GRANTS AND LOANS}

\section{Grant Ratio Trends by Region}

The grant to total bilateral aid ratio is increasing overall, but the extent of the increase shows considerable difference by recipient region. Bilateral ODA to Oceania was $100 \%$ grants for most of the period from 2000 to 2008 . For Africa, the grant ratio recorded $60 \%-80 \%$ up to the mid-1990s but increased thereafter to $80-100 \%$ as shown in Figure 3a. Grant ratio for the Americas 
show a similar level and changes over time. Notably, the grant ratio for Asia is considerably lower than those of Africa or Americas. The grant ratio for Asia records below $60 \%$, overcoming this threshold only after year 2000 . One possible reason for this regional difference may be because Asia's main donor is Japan, which mainly conducts ODA through concessional loans than grants. Another possible reason is that some Asian recipients, such as India, prefer loans to grants to avoid donor interventions. Grant ratio to Europe used to be higher than those for Africa and Americas but this has drastically declined since 2005.

\section{Figure 3. Trends in Grant Ratio by Recipient Region}

(a) Bilateral aid

Unit: \%
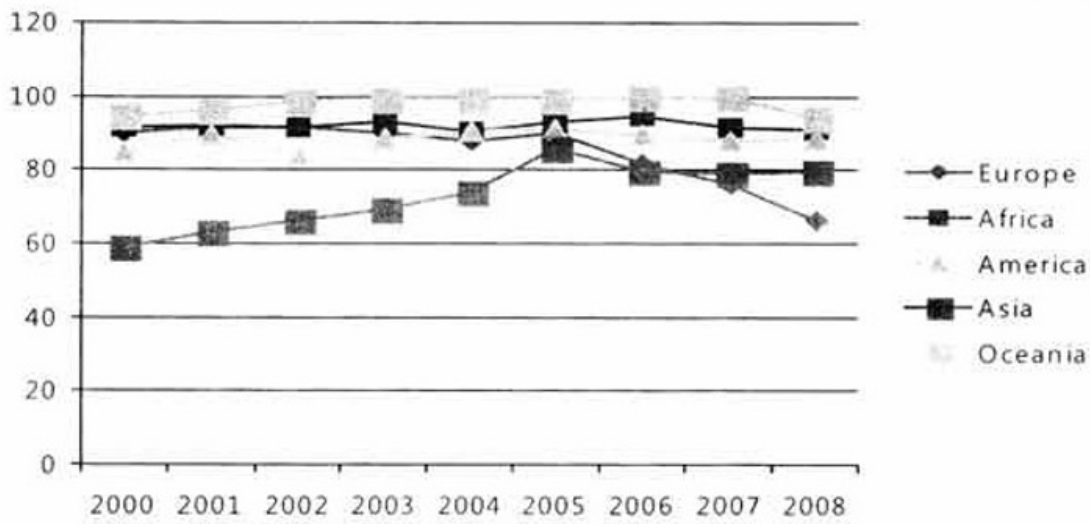

(b) Multilateral Aid

Unit: \%
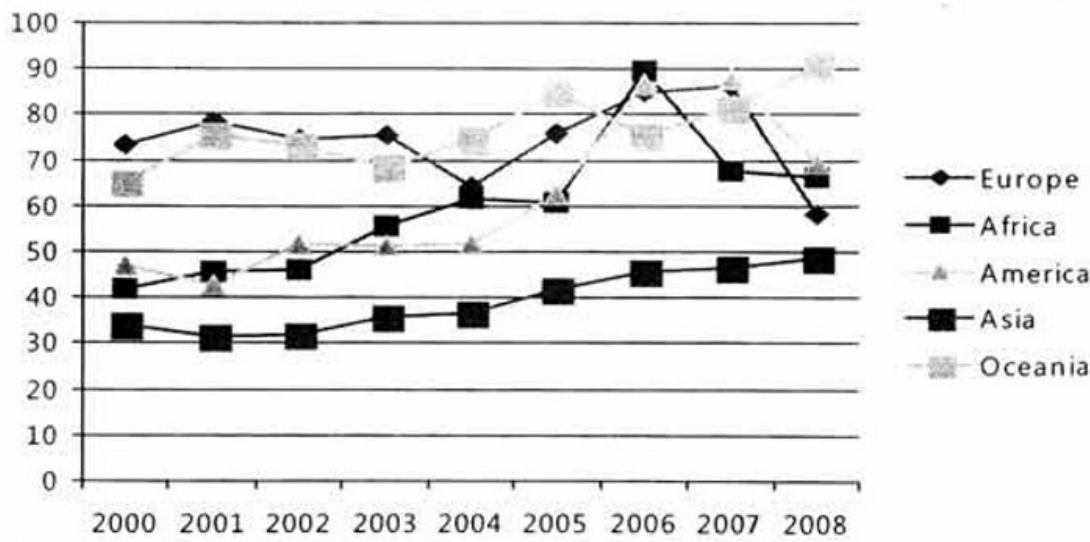

NOTE: Gross disbursement, 2008 prices.

SOURCE: Based on data from OECD DAC. 
Grant ratio of multilateral donors is maintained at less than $60 \%$ on average during 2000-2008. However, after extensive debt relief in 2005, this ratio has been increasing. It is highest for Oceania, with $76.62 \%$ on average. A similar grant ratio is found for Europe, but for Europe, the grant ratio is recently showing a decreasing trend. For Africa and Americas, the grant ratio of multilateral donors is also showing an increase, starting from a lowly $40 \%$ before 2005 . The grant ratio for Asia is again lowest as in bilateral ODA, but has consistently increased to reach $50 \%$ in 2008 (see Figure 3b). That is, while the grant ratio of multilateral donors is expectedly lower in general than that of bilateral donors since they are mostly development banks, the regional allocation pattern is similar between the two types of donors.

\section{Grant Ratio Trends by Recipient Income Levels}

The grant ratio of bilateral aid to all income groups is showing an overall increase. However, as in regional allocation, the increase shows considerable difference by income groups. The grant ratio is highest for the least developed countries, oscillating between $80 \%$ and $100 \%$. The grant ratio for other low income countries was lower than that for upper middle income countries, but is increasing rapidly, surpassing the grant ratio for upper middle income countries since 2004. The grant ratio was lowest for the lower middle income countries, but it has grown consistently to surpass the grant ratio for the upper middle income countries after 2000. Given that grant aid is considered to be more generous than loan aid, the above discussion shows bilateral aid to have a more desirable allocation pattern in general, with greater proportion of aid being provided through grants, the lower the recipient income levels, especially after 2000 (see Figure 4a).

The grant to loan allocation pattern by multilateral donors is different from that of bilateral donors. Figure $4 \mathrm{~b}$ shows that multilateral donors allocate more grants, the higher the income level of recipients. The grant ratio is highest for the upper middle income countries, recording $80-90 \%$, except for the year 2002. On the other hand, the grant ratio for other low income countries remained at a lowly $23-30 \%$ before 2005 , only reaching the $40 \%$ level in 2008 . Likewise, the grant ratio for least developed countries reached $60 \%$ only in 2008 , increasing from a previous $40 \%$ level. The grant ratio for lower middle income countries shows a similar trend. The hike in the grant ratio for least developed countries in 2005 is probably due to the effect of extensive debt relief undertaken in that year, rather than due to any increase in new grant aid itself (Joo et al. 2009).

\section{Overall Allocation by Modality and Sector}

The two major modes through which aid is delivered are grants and loans, 
Figure 4. Trends in Grant Ratio BY RECIPIENT INCOME leVEIS

a) Bilateral aid

Unit: \%

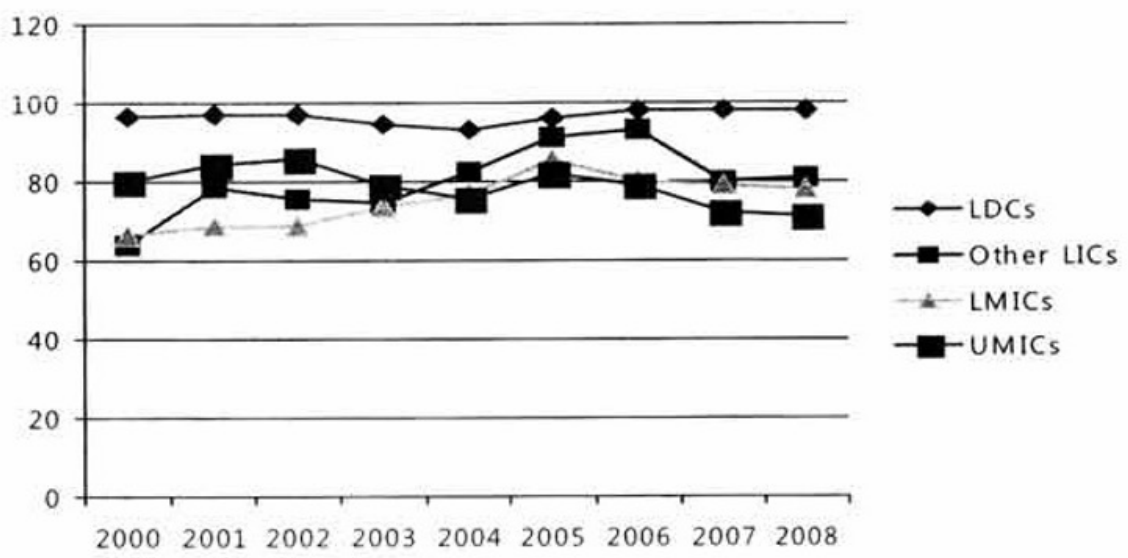

b) Multilateral aid
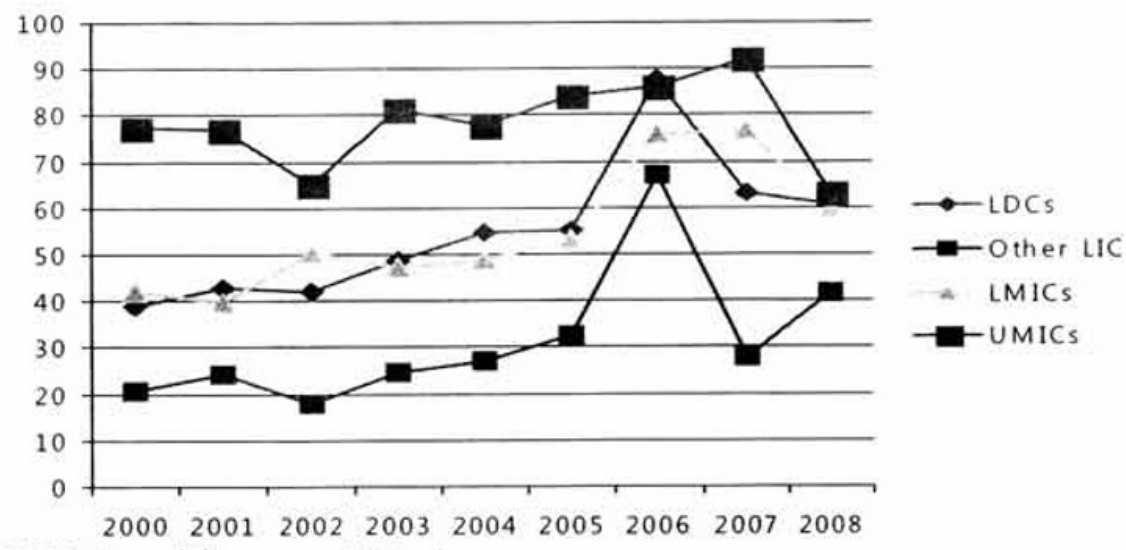

NOTE: Gross disbursement, 2008 prices.

SOURCE: Based on data from OECD DAC.

as we have seen above. Modalities for grant aid can be further distinguished into several other modalities: project aid, program aid, technical cooperation, humanitarian aid, provisions to NGOs and public-private-partnerships. Figure 5 shows the allocation of grant aid from the DAC countries as a whole by aid modalities. Most grant aid is disbursed through program aid and technical cooperation, with the proportion of program aid being slightly higher than that of technical cooperation. The next most prevalent modalities are humanitarian 
aid, debt relief, and project aid. Provisions to NGOs are substantial but public-private partnerships (PPPs) still remain at very low levels.

Figure 5. Overall. Aid Al.tocation of AID by Modal.iTy: DAC TOtal. in 2008.

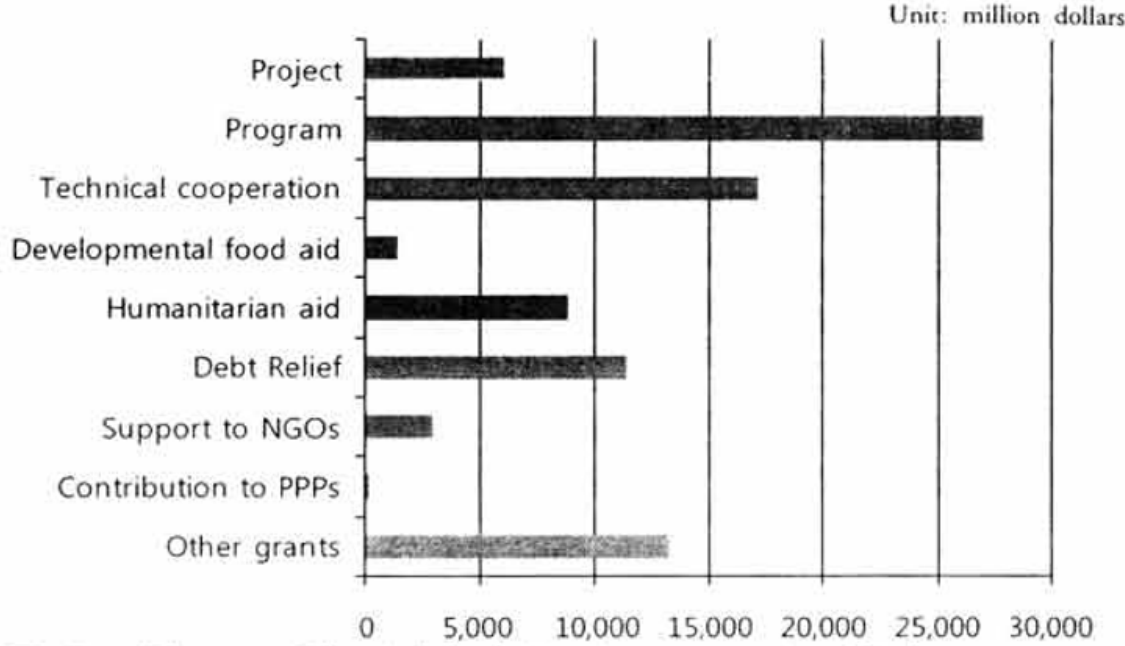

NOTE: Gross disbursement. Others include administrative cost, promotion of development awareness, and other unspecified allocations.

SOURCE: Based on data from OECD DAC.

Figure 6. Overal. Aid al.

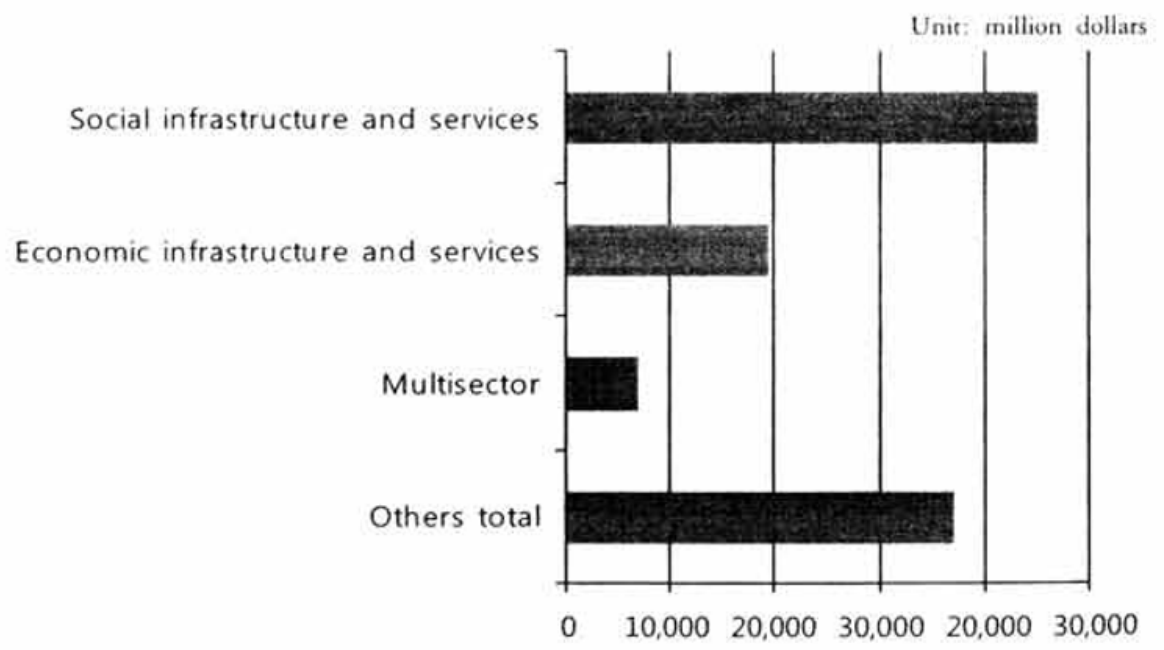

NOTE: Commitment basis. Others include humanitarian aid, administrative cost, support to NGOs. commodity aid, activities related to debt, refugees in donor countries, and other unspecified allocations.

SOURCE: Based on data from OECD DAC. 
Aid can also be classified by the various purposes to which it is channeled. The OECD DAC identifies four main sectors: Social and administrative infrastructure, Economic infrastructure, Production, Multi-sector, and Others. OECD DAC statistics on ODA by sector is generally provided in terms of commitment rather than actual disbursement. Therefore, although we may not be able to gauge actual trends of aid allocation by sector, we may still be able to discern a donor's policy with respect to sectoral allocation. At the overall level, social infrastructure and services take up most of the aid coming from the DAC countries taken together, as of 2008. Humanitarian aid and economic infrastructure and services take up the next largest portion. ODA allocation to multi-sector and production takes up around $10 \%$ each, respectively (see Figure 6). A substantial portion belong to the other category, which includes humanitarian aid, administrative cost, support to NGOs, commodity aid, activities related to debt, refugees in donor countries, and other unspecified allocations.

\section{Grant-Loan Allocation Across Modalities and Sectors}

Grant-loan allocation by modalitics and sector is mainly explored by comparing the behavior of two types of bilateral donors: the grant oriented group and the loan oriented group, as classified in Section II. Figure 7 clearly shows that the major means through which grant and loan oriented donors disburse their aid are different. By and large, grant oriented donors used program aid much more than project aid. Grant oriented donors engaged in technical cooperation to a certain extent but not as much as loan oriented donors. Humanitarian aid and support to NGOs did not take up large proportions overall, but grant oriented donors engaged in these modalities much more than their loan oriented counterparts.

Loan oriented donors focused on technical cooperation as the major modality of aid disbursement. They also focused more on project aid compared to program aid, unlike their grant oriented counterparts. Understandably, for loan oriented donors, debt relief took a large proportion of total grant disbursed. On the other hand, they provided only low levels of humanitarian aid and support to NGOs. Food aid and contributions to public-private partnerships (PPPs) constitute only very small portions for both types of donors. On the other hand, both types, especially the grant oriented donors, show a substantial use of "Other" modalities. Upon closer inspection of this category, it is shown that while grant oriented donors engaged in assisting refugees in donor countries much more than loan oriented donors, administrative costs are somewhat greater for loan oriented donors (see Figure 8).

It is a little more difficult to discern a difference in patterns of aid allocation by sector between grant and loan oriented donors since both types channeled a substantial amount of aid into social infrastructure and other sectors. Nevertheless, 
it is clear from Figure 9 that while grant oriented donors focused relatively more on social infrastructure, loan oriented donors concentrated relatively more on economic infrastructure and production sectors. This difference can easily be explained by the natural division of labor between grant and loan aid, since the latter involves large scale developmental projects that require greater financing than smaller scale social infrastructure projects.

\section{Figure 7. Allocation by Modality: Comparison Between Grant and Loan ORIENTED DONORS (2008)}

Unit: \%

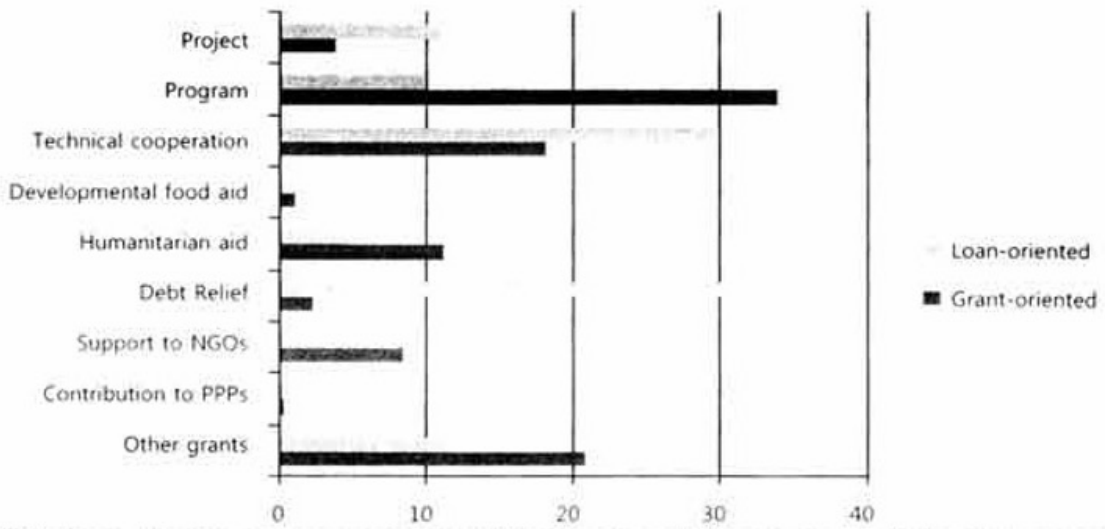

NOTE Gross disbursement, current prices basis. Other grants include promotion of development awareness, administrative costs, refugees in donor countries, grants in grant-loan packages, and orher grants. SOURCE: Based on data from OECD DAC

Figire 8. Allocation of "Other" MOdalities: Comparison of Grant AND LOAN ORIENTED DONORS (2008)

Unit: \%

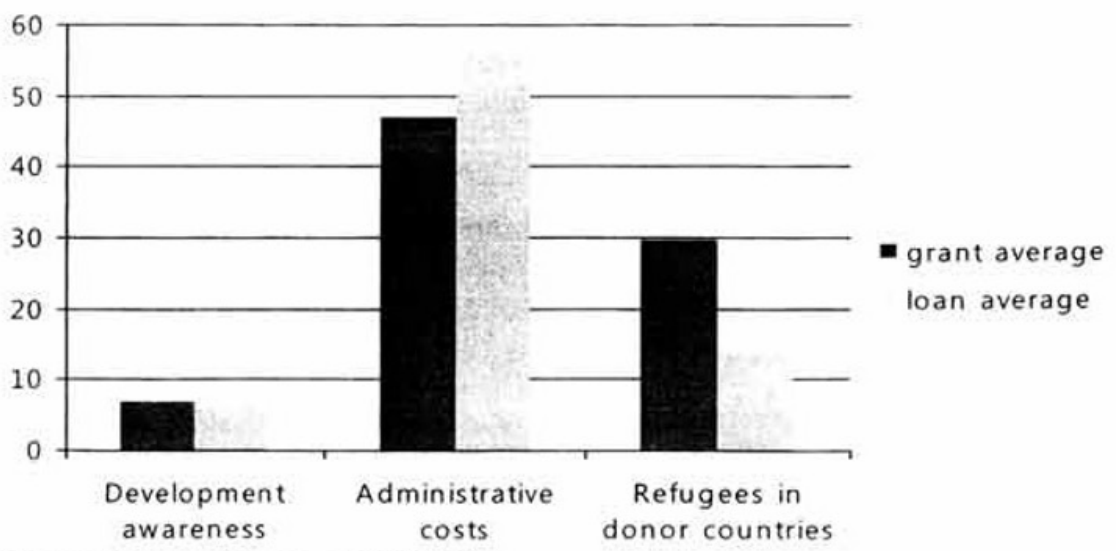

SOURCE; Based on data from OECD DAC 
Figure 9. allocation by Sector: Comparison Between Grant and loan ORIENTED DONORS (2008)

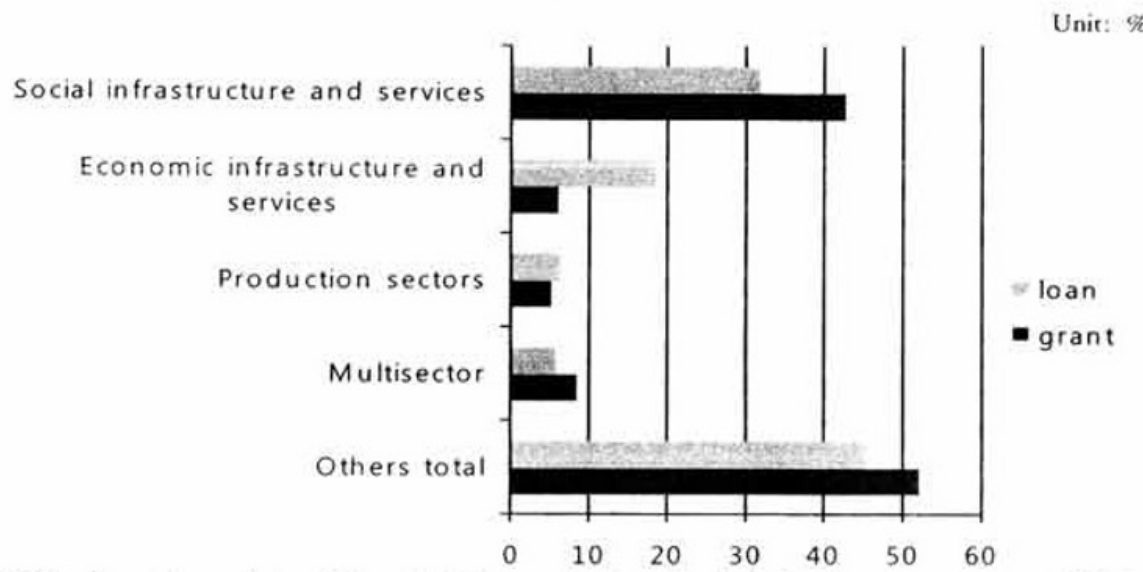

NOTE: Commitment basis. Others include humanitarian aid, administrative cost, support to NGOs. commodity and, activities relared to debr, refugees in donor countries, and other unspecitied allocations

SOURCl: Based in data from OECD DAC.

Since both types channeled a substantial amount to social infrastructure and other sector category, it would be important to look at a more desegregated level to explore if the two types of donors focused on different sub-sectors within these sectors. At the same time, although grant oriented donors committed relatively less to the production sectors but relatively more to the multi-sector, the difference is not very great. Therefore, for these sectors also, it would be important to see if there is any difference between the two types of donors at the sub-sector level. Figure 10 compares grant and loan oriented donor commitments to different subsectors within social infrastructure and services. In general, grant oriented donors committed relatively more to education compared to loan oriented donors, but loan oriented donors showed relative strength in secondary education, and assisted post-secondary education substantially. Grant oriented donors were also the major donors in health and population policy but loan oriented donors committed slightly more to health in general. Further, loan oriented donors committed substantially more to water supply and sanitation compared to grant oriented donors, possibly because it is an area which needs larger scale infrastructure building. On the other hand, grant oriented donors paid more attention to those aspects concerning institutional building and governance such as government and civil society, conflict, peace and security, and the remaining other social infrastructure subsectors.

Figure 11 compares grant and loan oriented donor commitment to different subsectors within the other sectors category. These subsectors are those that are difficult to assign a specific field, and look more like sub-categories of aid 
modalities discussed above. Grant oriented donors tended to commit notably more to general budget support, emergency response, and refugee assistance in donor countries. On the other hand, most of the loan oriented commitment in the other sectors went to debt related activities. Unexpectedly, seen as a proportion of sectoral allocation, administrative cost was larger for grant oriented donors rather than loan oriented donors.

Figurf 10. Social. Infrastructure and Services: Sub-Sector Alilocation by TYPES OF DONORS

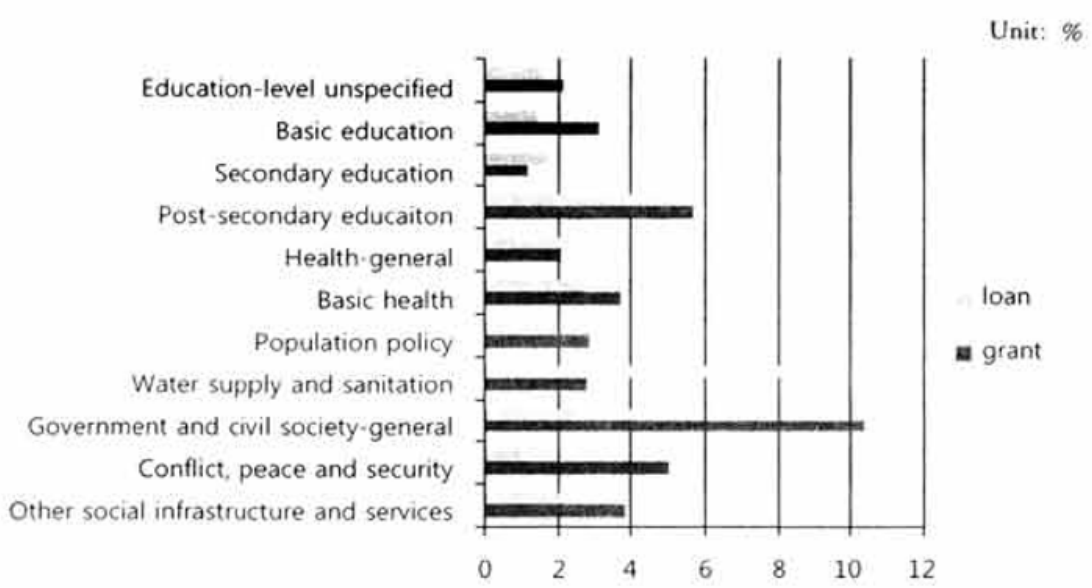

NOTE: Commitment basis. Government and civil society includes aid related to conflict, peace and security:

SOURCE: Based on data from OECD DAC.

Figlire 11. Other Sectors: Sub-Sector Alllocation by Types of Donors

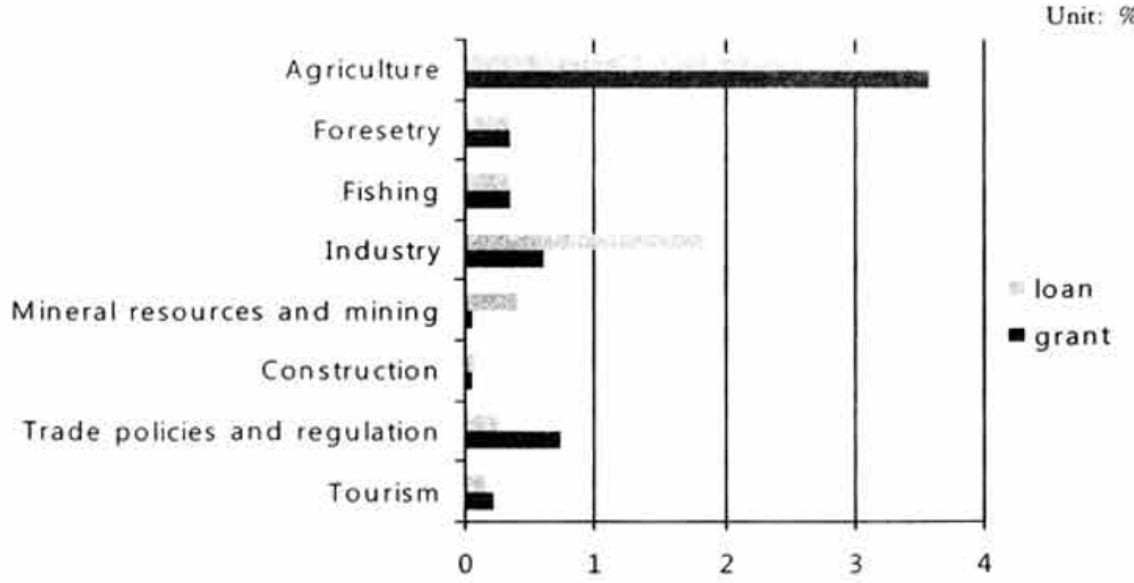

SOURCE: Based on data from OECD DAC. 
Finally, Figure 12 compares grant and loan oriented donor commitments to different subsectors within production sectors and the cross-cutting, multi-sectors. Within the production sectors both types of donors committed the most to agriculture, with grant oriented donors providing a little more to this subsector. However, both types of donors allocated similar amounts to forestry and fishing. Loan oriented donors were the major donors in industry, mineral resources and mining, while both types of donors allocated similarly small amounts to construction. Grant oriented donors showed relative strength in tourism and institutional building related activities such as trade policies and regulation. While grant oriented donors allocated more to the multi-sector in general, loan oriented donors allocated a slightly greater proportion of aid generally to environmental protection on average.

\section{Figure 12. Protuction Sectors and Mutiti-Sector: Sub-Sector Aliocation BY TYPES OF DONORS}

(a) Production Sectors

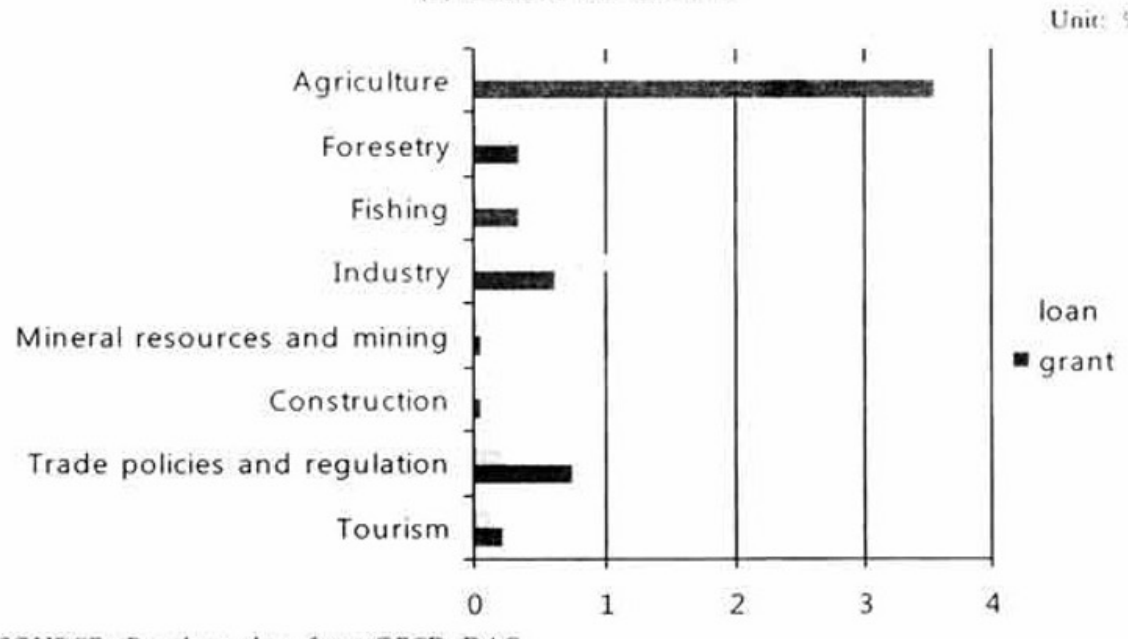

SOURCE: Based on data from OECD DAC.

(b) Multi-Sector

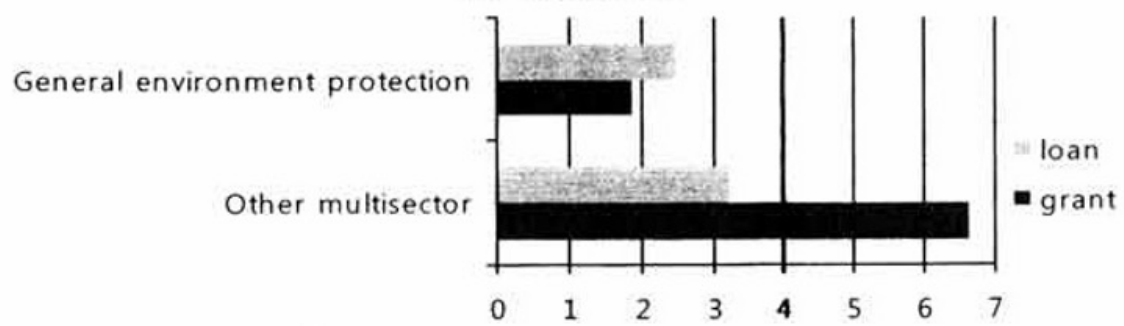

SOURCE: Based on data from OECD DAC. 


\section{Division of Labor Between Grants and Loan Aid}

In previous sub-sections of Section IV, it was shown that regional allocation patterns of grant aid by bilateral and multilateral aid were similar, and did not show any division of labor, although in general, the grant ratio of multilateral donors was lower as expected. However, there was a clear difference in the way the two types of donors allocated grant to different income level groups. While the grant ratio for bilateral aid was greater the lower the recipient income level in general, the grant ratio for multilateral aid was greater the higher the recipient income. Given that grants are considered to be a more generous form of aid, this pattern of grant versus loan allocation apparently contradicts the allocation patterns of overall bilateral and multilateral aid discussed in Section III. There, it was shown that while bilateral allocation decision tended to be donor interest driven, multilateral allocation decision tended to be based more on recipient needs and policy performance.

One reason why the grant ratio of multilateral concessional loans tend to be higher for higher income developing countries than lower income developing countries is because of the allocation behavior of regional development banks. Leaving out contributions from UN agencies and various specific purpose funds which are $100 \%$ grants, and comparing just major international financial institutions, Figure 13 shows that only the IDA and the Caribbean Development Bank had higher grant ratios for LDCs and other lower income countries. Other regional development banks, including the African Development Bank, had much

Figure 13. Multulateral. Financial Instititions: Grant Ratios bi income Unit: \%

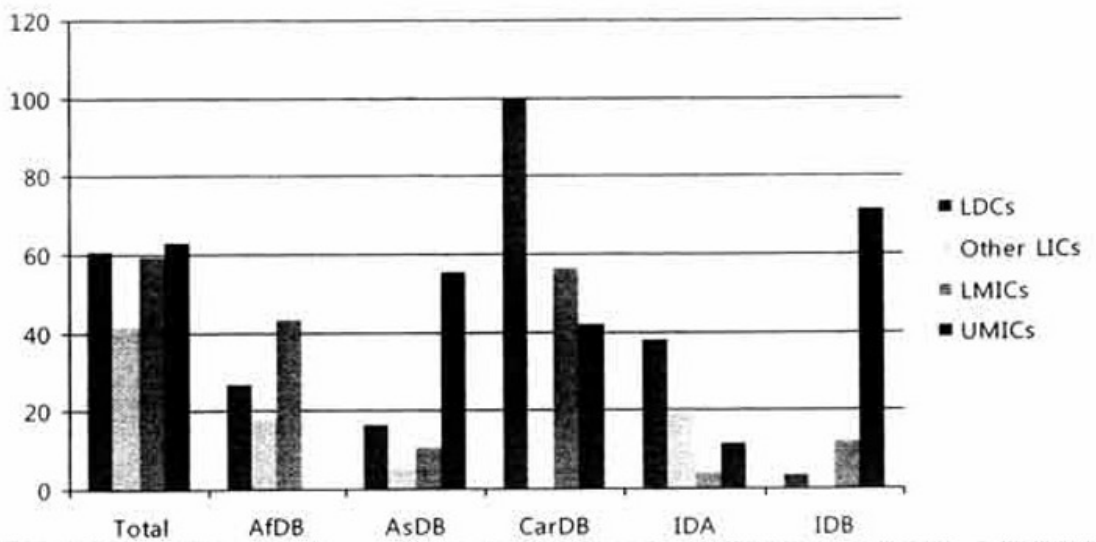

NOTE: $\mathrm{AfDB}=$ African Development Bank, AsDB $=$ Asian Development Bank, CarDB $=$ Caribbean Development Bank, IDA = International Development Agency, IDB = Inter-American Development Bank.

SOURCE: Based on data from OECD DAC. 
higher grant ratios for lower or upper middle income countries. Although the IDA takes up the greatest share of concessional flows among international financial institutions, its grant ratio for the LDCs does not rise over $40 \%$. On the other hand, the grant ratio for middle income countries by regional development banks range from around $60 \%$ to $70 \%$. This is consistent with observations of Mascarenhas and Sandler (2005), who argues that regional institutions do behave differently from multilateral institutions, and tend to be too rigid to take into account variables that affect efficient allocation (e.g., public goods nature of aid projects).

The division of labor between grants and loans in aid modalities and sectors was explored mainly by comparing grant oriented donors and loan oriented donors. Grant oriented donors are shown to focus more on program aid and humanitarian aid. They also contribute relatively more to NGOs, refugees in donor countries and post conflict peace building operations. On the other hand, loan oriented donors focus more on project aid and technical cooperation. The two types of donors also had distinct sectors of specialization. While grant oriented donors focused relatively more on social infrastructure and others (which includes commodity aid, budget support, emergency response, reconstruction and rehabilitation, refugees in donor countries and disaster prevention), loan oriented donors focused relatively more on economic infrastructure and services. However, loan oriented donors also contributed substantially to social infrastructure, especially in water supply and sanitation, surpassing contributions of grant oriented donors in these sub-sectors.

Within the production sectors, to which both types of donors contributed similar amounts of aid, a division of labor could again be found. While grant oriented donors focused relatively more on agriculture and tourism, and institutional building activities such as trade policies and regulation, loan oriented donors paid relatively more attention to industry, mineral resources, and mining. At the same time, while grant oriented donors contributed more to the multi-sector category, loan oriented donors surpassed grant oriented donors in environmental protection.

\section{KOREA'S ROLE AS AN EMERGING DONOR}

\section{Characteristics of Korean $O D A$}

This section examines the trends in Korean ODA to explore Korea's comparative advantages and possible coordination strategies in the light of the current division of labor between grant and loan aid discussed in previous sections. Korea's ODA has consistently increased to record US $\$ 820$ million (current prices, total expenditure basis) in 2009. Of this $30 \%$ constitutes contributions to multilateral aid institutions. The ODA to GNI ratio is a miniscule $0.1 \%$ as of 2009 , but 
this is five times the 1987 level, which is a tremendous increase from the perspective of Korea. The grant ratio of Korea's total ODA has also been increasing since 2002 , recording $50 \%$ on average during the last decade.

Korea's bilateral aid is primarily focused on Asia. In the 2000s, around $70 \%$ of its total aid flowed to Asia. However, since 2005, aid to Africa is increasingly replacing aid to Asia. This reflects Korea's recent policy to diversify its ODA destinations. Bilateral aid to the European region has clearly declined, while aid to Oceania does not show a definite trend (see Figure 14a).

Figure 14. Korea's ODA Allocation Trends

(a) Regional Allocation

Unit: \%

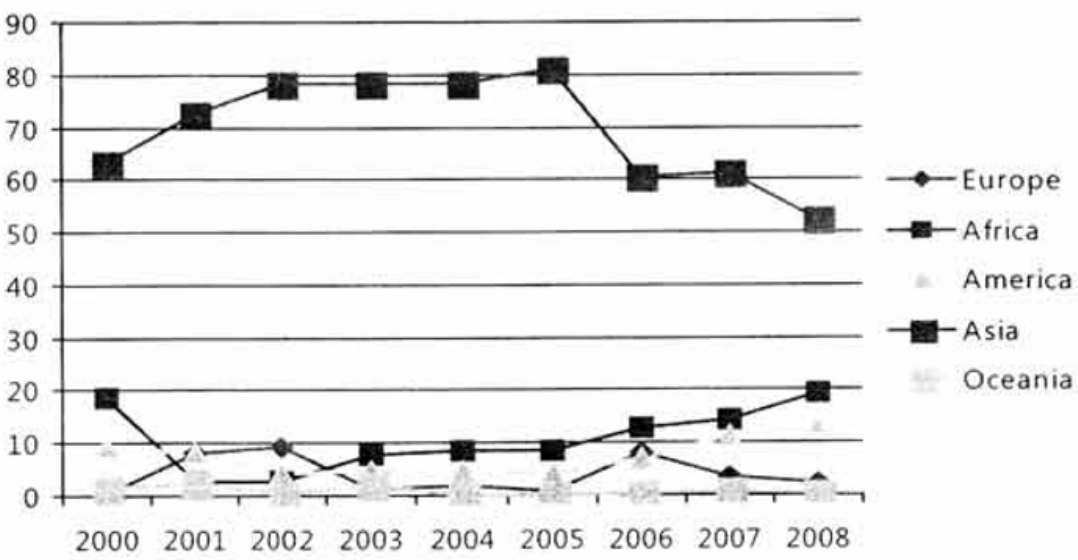

(b) Allocation by Recipient Income Levels

Unit: \%

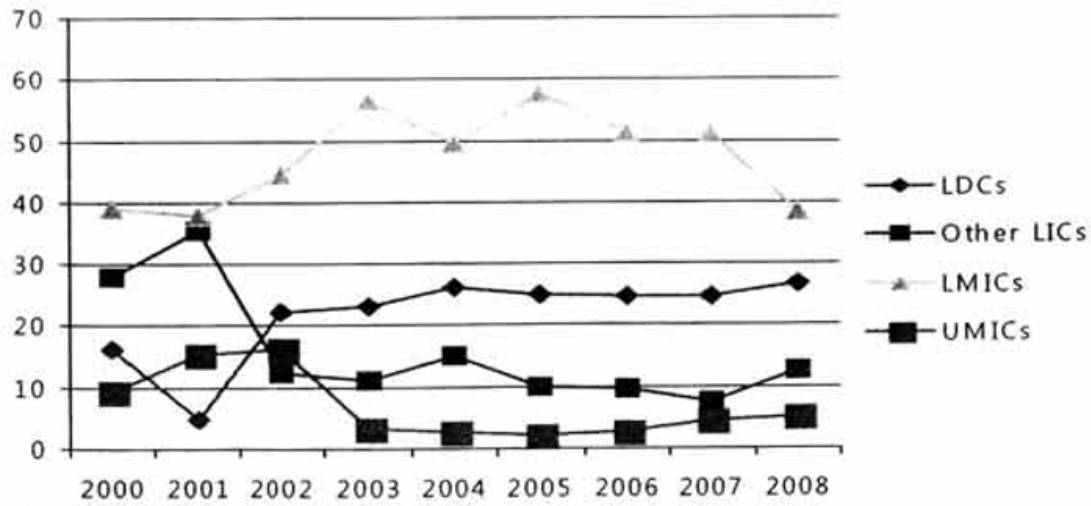

NOTE: Gross disbursement, 2008 prices.

SOURCE: Based on data from OECD DAC. 
At the same time, Korea's overall aid allocation has been greatest to lower middle income councries, forming $47.37 \%$ on average during 2000-2008. This is very much in tune with the general bilateral aid allocation pattern. The next priority income level groups are least developed countries $(21.5 \%)$, other low income countries $(15.7 \%)$ and then upper middle income countries $(6.8 \%)$. During 2000-2002, aid allocation to high middle income countries was greater than that for least developed countries and other low income countries, but since 2002, the allocation pattern has become more desirable, with allocation to least developed countries and other low income countries surpassing that of upper middle income countries (see Figure 14b).

The same regional pattern is found in the case of Korea's grant aid allocation as seen in the general international trend (see Figure 15a). Grant ratio to Oceania is $100 \%$ since 2003. On average, the grant ratio for Africa, Americas, and Asia is maintained at around $50 \%$, although it is the lowest for Asia. Nevertheless, grant ratio for Asia increased since 2003, with increasing grant aid to countries undergoing conflict such as Afghanistan and Iraq. On the other hand, with increasing overall aid to Africa, the grant ratio for Africa surpassed that of Asia in 2007. On the contrary, the grant ratio for European developing countries shows a low $12 \%$ average during 2000-2008.

In the case of Korean ODA, the grant ratio was the highest for least developed countries before 2003, but thereafter, the grant ratio is the highest for upper middle income countries. The grant ratio for lower middle income countries is lower than that for upper middle income countries but higher than that for least developed countries, since 2003. That is, the grant ratio was higher the higher the income level of recipient countries, following the pattern of multilateral donors. This is exactly opposite to what one may expect or is desirable. Fortunately, however, Figure 15b shows that the grant ratio is improving for the least developed countries recently. In addition, the grant element of concessional loans from the EXIM Bank of Korea using the Economic Development Cooperation Fund (EDCF) is $87.4 \%$, much more generous than the DAC average of $67.1 \%$. Furthermore, the grant element is designed in such a way so that it will increase, the lower the income levels of recipients. In light of recent empirical evidence regarding the importance of concessionality in loan aid discussed in Section II, this is a positive feature in Korean ODA.

Korea's allocation of ODA by aid modalities shows similar patterns as other loan oriented donors. However, except for the substantial concentration of aid for technical cooperation, Korea allocates its ODA to almost all other modalities fairly evenly. This implies that Korea's ODA has not yet found a modality of expertise or specialty, except for technical cooperation. This would restrict Korea's opportunities to take up the roles of lead or active donors in many situations. 
Figure 15. Grant Ratio Trends in Korea's oda

(a) Grant Ratio by Region

Unit: \%

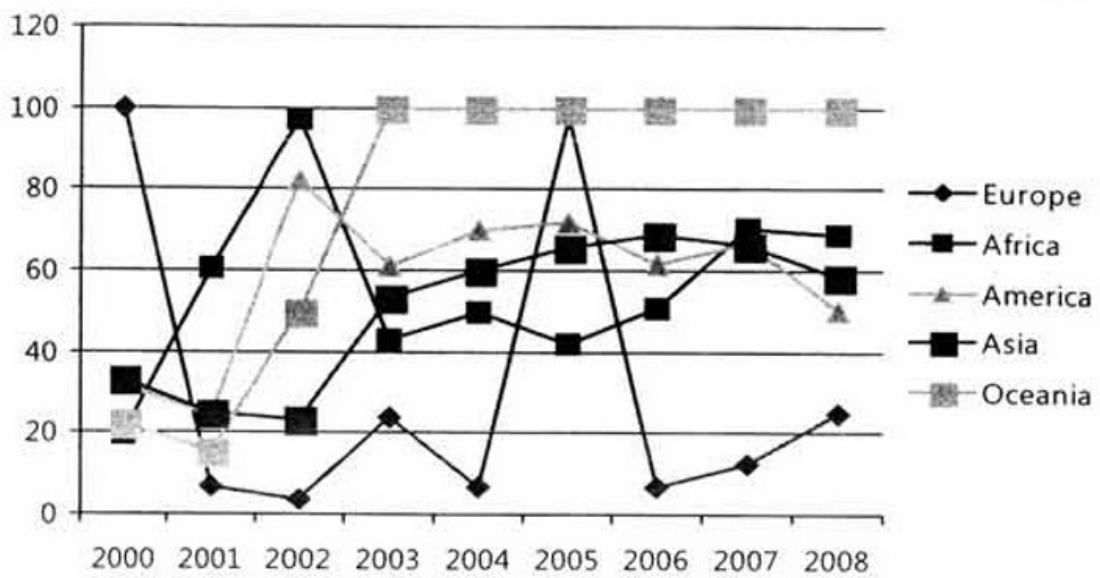

(b) Grant Ratio by Income Levels

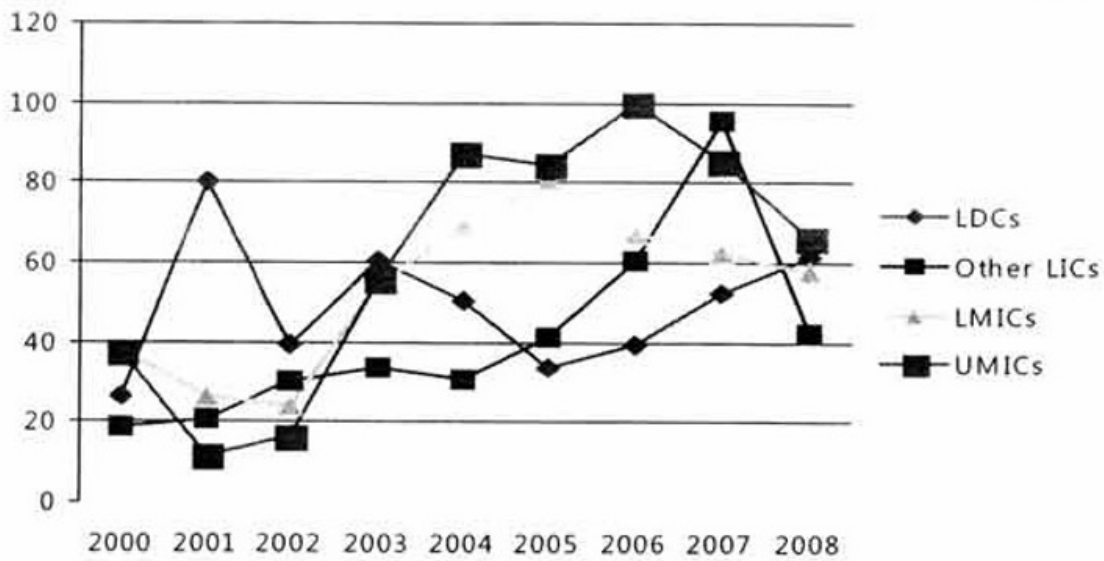

NOTE: Gross disbursement, 2008 prices.

SOURCE: Based on data from OECD DAC.

The evolution of patterns in Korea's allocation of aid to different aid modalities can be better seen in Figure 16. The three modalities of aid that take up the largest proportion are project aid, program aid, and technical cooperation. These three modalities are substitutes. The increase in one modality causes a decrease in the other. During 2002-2005, proportion of technical cooperation declined to give way to project and program based aid, while after 2005 , technical cooperation 
is taking up most of grant aid. Humanitarian aid in Korean ODA is maintained at around $10 \%$ through out the period from 2000 to 2008 . This shows that Korea's primary form of grant aid is technical cooperation.

Figure 16. TRENDS IN Korea's ODA by MODAlity

(a) Allocation by Modality

Unit: \%

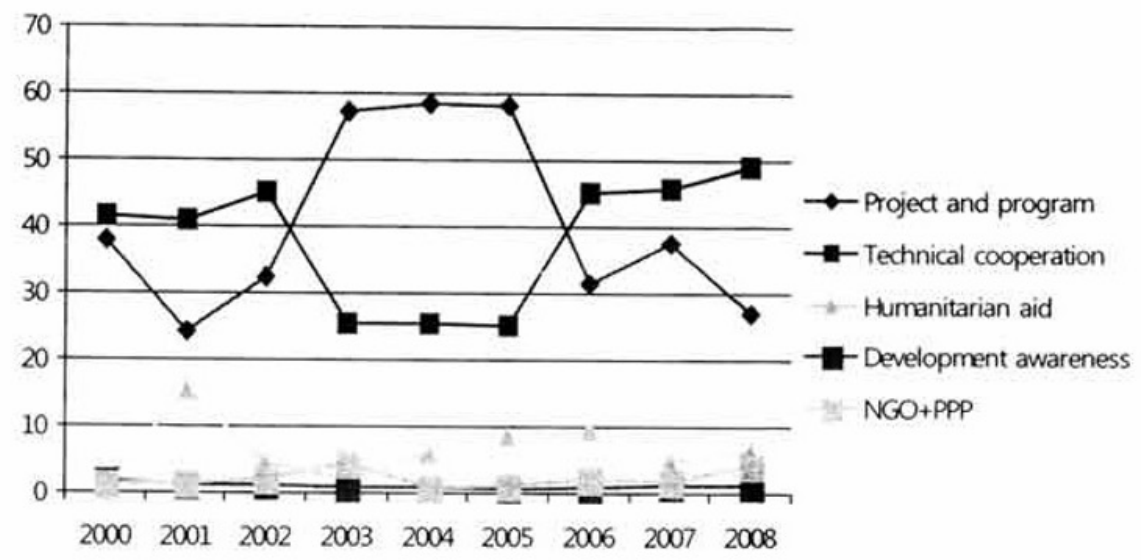

(b) Trends in Project and Program Aid

Unit: million dollars

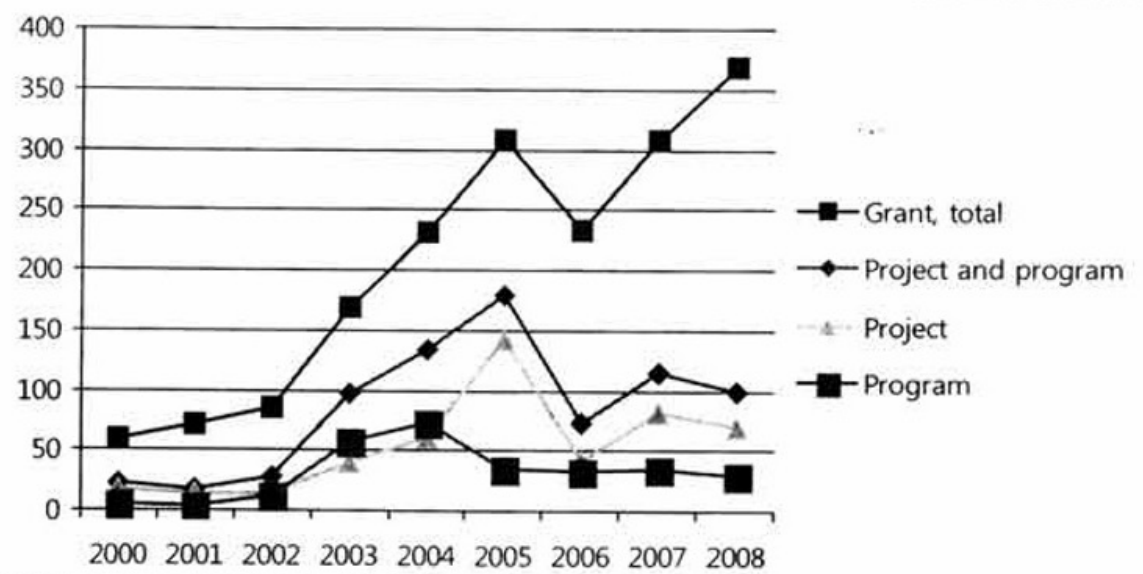

NOTE: Gross disbursement, 2008 prices.

SOURCE: Based on data from OECD DAC

Figure 17 shows changes in the sectoral allocation of aid for Korean ODA over the period from 2000 to 2008. Most of Korean ODA is allocated to social 
infrastructure in general. Within social infrastructure, Korean ODA showed strength in water supply and sanitation, basic health and secondary education, similar to other loan oriented donors. Korea's allocation to economic infrastructure shows big increases since 2005, but still shows lower levels than social infrastructure. Allocation to other sectors such as production, humanitarian aid and multi-sector consistently remains at low levels below $10 \%$. Fluctuation in allocation to production is especially high year to year, which is an element of concern from the perspective of aid predictability.

Figure 17. Korea's ODA Al.tocation by SECtor

(a) Trends in Sectoral Allocation

Unit: \%

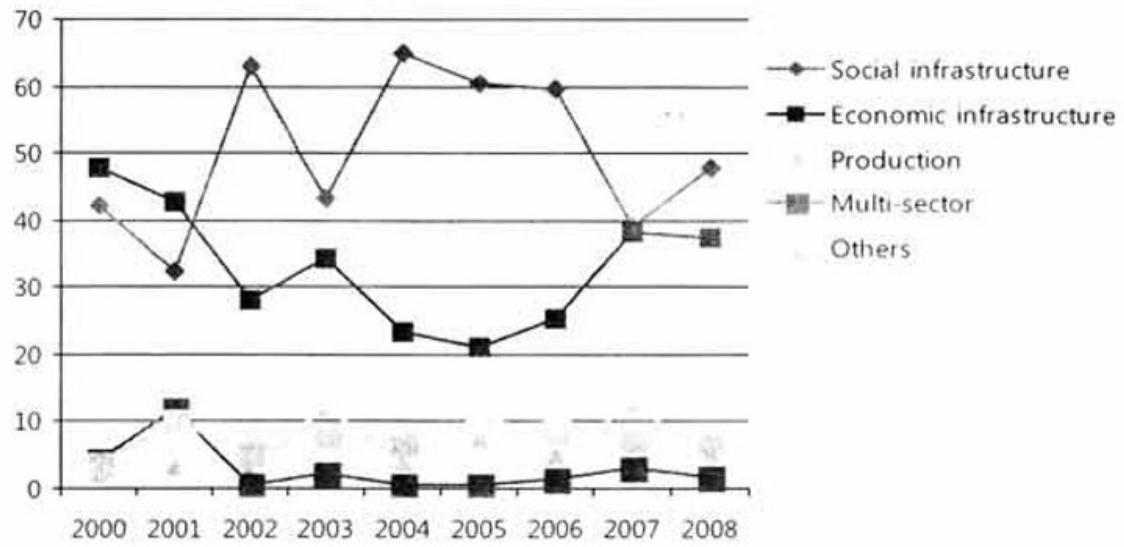

(b) Allocation by Sub-Sectors in Social and Economic Infrastructure

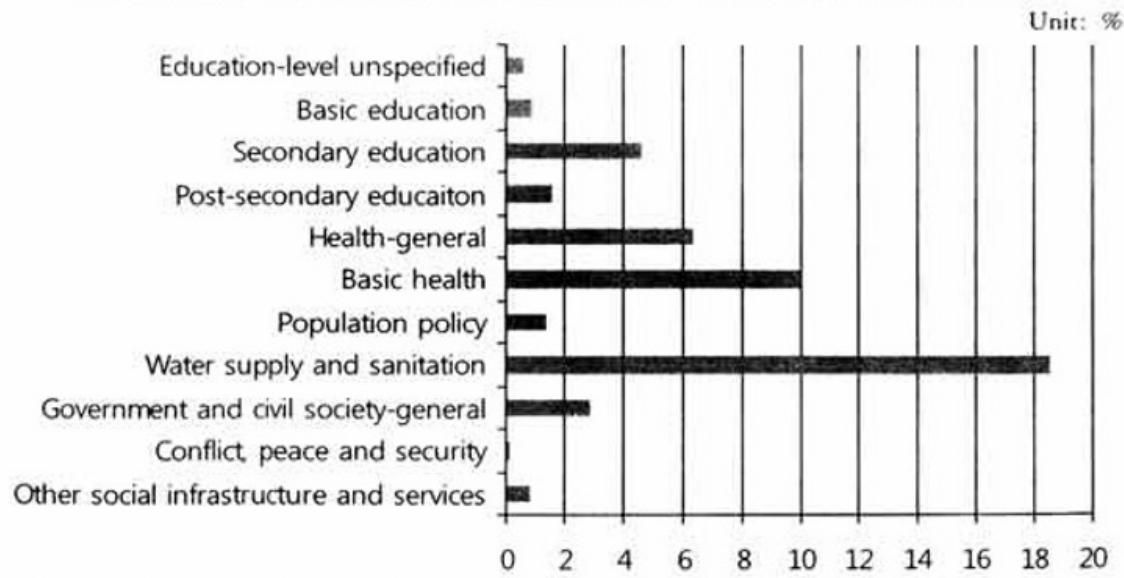

SOURCE: Based on data from OECD DAC. 


\section{Strategies for Aid Coordination: Korea's Role}

Given that there is a division of labor between bilateral and multilateral donors, Korea's ODA could have a greater synergistic effect if it strengthens cooperation with multilateral donors rather than competes with other bilateral donors in providing aid to recipients with similar characteristics. Synergy effects with multilateral donors could be devised in many ways, for example through providing flexible grants and technical cooperation at the preparatory and post-completion stages, including long term maintenance activities of a loan project. Such assistance will enhance aid effectiveness and sustainability through increased recipient capacity due to up front technical cooperation and aid sustainability by giving greater attention to post-completion stages. Unlike simply filling a financing gap, this type of cooperation requires a more complex and advanced level of coordination. Korea has just begun to prepare Country Strategy Papers for priority countries. It should be considered whether this should be replaced by JAS for some countries so as to enhance coordination with major multilateral donor institutions that have already adoped this approach.

At the same time, given that there are distinct areas of specialization between grant oriented donors and loan oriented donors, and that Korea's ODA is mainly disbursed through technical cooperation on project basis, mostly to sectors such as social infrastructure, it is possible to think of two differentiated strategies by which Korea can strengthen its cooperation with other bilateral donors depending on the type of donors. With other loan oriented donors, Korea should provide additional aid to finance augmenting successful projects already operated by other donors, since all loan oriented donors will be running similar types of aid projects in similar sectors. In this case, Korea's role is mainly that of facilitating "scaling-up."

On the other hand, with grant oriented donors which primarily support different types of aid programs in different sectors from Korea's ODA, the strategy should be to maximize complementarities within a certain program, taking charge of specific small projects through various modalities such as providing additional loan finance and technical cooperation, or expanding the overall scope of the program to cover sectors unlikely to be covered by grant oriented donors but in which Korea has relative strength (e.g., secondary or post secondary education, basic health, water supply and sanitation). That is, Korea could take up the role of an "active donor" in the parlance of Murle (2007) in these areas of comparative advantage within an overall joint aid program.

In regions where Korea has a large presence, as in Asia or lower middle income countries, Korea could take up the role of a "lead-donor," undertaking overall program coordination with the recipient government. It would also be possible for Korea to expand the scope of the program into different regions, for example, "spreading-out" locally successful cases to the national level or 
to other countries. This kind of cooperation with other bilateral donors would give grant-loan package aid, which currently stands at very low levels, a more dominant role to play.

\section{CONCLUSION: CROSS-INSTRUMENT DIVISION OF LABOR IN ODA AND POLICY IMPLICATIONS}

Although this paper relies on a very simple analysis, it gives one of the first overall characterizations of cross-instrument international division of labor in ODA, offering insights on general cooperation strategies that Korea can adopt to maximize the impact of its aid, which still remains at low levels. Focusing on grant-loan coordination, the study found that the international division of labor in ODA has emerged along two dimensions: one between bilateral and multilateral donors, and another between grant oriented and loan oriented donors. The division of labor that has emerged between bilateral and multilateral aid in terms of regional and income level allocations show that bilateral donors focus more on middle income countries but is geographically more widespread, while multilateral donors focus more on low income countries and Africa.

There does not seem to be any division of labor between grant and loan aid with respect to regional allocation. Grant ratio by all cypes of donors, including Korea, is increasing in all regions. However, there was a distinct difference between bilateral donors and multilateral donors with respect to how they treat recipients depending on their income levels. While bilateral donors followed a more needs-based policy, providing greater grants to poorer regions, multilateral donors and Korea provided greater grants to higher income groups. It is not clear why this has come to be the case. For the multilateral donors, regional development banks certainly seem to have a role in setting this trend. In the case of Korea, although the overall grant ratio is higher for the middle income group, the grant element is designed to increase for recipient groups with lower GNI per capita. This is a desirable feature, given that the degree of concessions is potentially more important than the size of the loans for aid effectiveness.

The international division of labor in ODA by modality and sector was examined mainly by comparing grant oriented and loan oriented donors. Grant oriented donors concentrate on program aid, humanitarian aid, and contributions to NGOs. They also allocate a greater portion of aid allocated to multi-sector and humanitarian aid compared to loan oriented donors. On the other hand, loan oriented donors concentrate relatively more on technical cooperation and economic infrastructure. However, both types of donors allocate a substantial amount to social infrastructure, and smaller but similar amounts to production sectors. Different relative strengths by different types of donors seem to have emerged within these sectors. In general, grant oriented donors concentrated more on subsectors such as health 
and education, and paid greater attention to institution building and governance, while loan oriented donors showed relative strength in secondary education, water supply and sanitation, and general environmental protection.

The division of labor between grant and loan aid that has emerged is particularly interesting. It is shown that grant and loan aid have respective roles in different sub-sectors and modalities of aid, suggesting that grant and loan aid can complement each other to create synergies. This has important implications to the long-running debate in Korea with respect to which form of aid - grant or loans-should take primacy. The evidence from this paper helps us to conclude that such kind of debate is a futile one.

Given that the international division of labor in ODA and characteristics of Korean ODA, it is possible to elicit three main implications for Korea's strategy in strengthening cooperation with other donors. First, considering the bilateral-multilateral division of labor that has emerged, Korea's potential for strengthening cooperation seems to lie more with multilateral donors than other bilateral donors. Second, with other loan oriented donors, it should mainly cooperate through augmenting successful aid projects or programs in similar areas (i.c.. a scaling-up strategy). Third, with grant oriented donors, it should cooperate by going into complementary areas of aid within an aid program, or complementing certain aid projects or programs through technical cooperation or loan financing (i.e., geographic or sectoral "spread-out" strategy). While Korea should not be precluded from building up its comparative advantage in areas that are not of its current strengths, the strategies discussed here will enhance Korea's ODA impact by facilitating greater coordination with other donors.

\section{REFERENCES}

Collier, Paul and David Dollar. 2001. Can the World Cut Poverty in Half? How Policy Reform and Effective Aid Can Meet International Development Goals. World Development 29(11): 1787-1802.

Djankov, Simeon, Jose Motalvo, and Maria Reynal-Querol. 2009. Aid with Multiple Personalities. Journal of Comparative Economics 37(2): 217-229.

Dreher, Axel and Katharina Michaelowa. 2010. Methodology to measure progress towards in-country division of labor. Final Report. Input material for the Task Team on Division of Labor and Complementarity under the Working Party on Aid Effectiveness, OECD DAC.

Easterly, William. 2003. The cartel of good intentions: the problem of bureaucracy in foreign aid. Journal of Policy Reform 5(4): 1-28.

Economic Development Cooperation Fund. 2010. Internal Memo.

Frot, Emmanuel and Javier Santiso. 2010. Herding in Aid Allocation. OECD Development Centre Working Papers 279. Paris: OECD. 
Hoeffler, Anke and Verity Outram. 2008. Need, Merit, or Self Interest-What Determines the Allocation of Aid. Centre for the Study of African Economies. WBP.

limi, Atsushi and Yasuhisa Ojima. 2008. Complementarities between grants and loans. Journal of Japanese and International Economy 22: 109-141.

Joo, Dong-Ju, Hak-ki Kim, Kye-whan Kim and Seouk-whan Kim. Analysis of ODA by Developed Countries and Strategies for Korean ODA (in Korean). Commissioned report. Seoul: EDCF, Korea EXIM Bank, and Korea Institute for Industrial Economics and Trade.

Kanbur, Ravi and Andy Sumner. 2011. Poor Countries or Poor People? Development Assistance and the New Geography of Global Poverty. http:// kanbur.dyson cornell.edu/papers.htm.

Kimura, Hidemi, Yasuyuki Sawada, and Yuko Mori. 2007. Aid Proliferation and Economic Growth: A Cross-Country Analysis. RIETI Discussion Paper Series 07-E-044.

Knack, Stephen and Aminur Rahman. 2008. Donor Fragmentation. In ed. William Easterly. Reinventing Foreign Aid. Massachusetts: MIT Press.

Mürle, Holger. 2007. Towards a Division of Labour in European Development Cooperation: Operational Options. DIE Discussion paper. Bonn: German Development Institute. 6 .

Nissanke, Machiko. 2010. The Aid Effectiveness Debate. In ed. George Mavrotas. Foreign Aid for Development: Issues, Challenges, and the New Agenda. Oxford: Oxford University Press.

Odedokun, Matthew. 2004. Multilateral and Bilateral Loans versus Grants: Issues and Evidence. World Eionomy 27(2): 239-263.

OECD DAC Database 2000-2008.

Riddell, Roger C. 2007. Does Foreign Aid Really Work? Oxford: Oxford University Press.

Schabbel, Christian 2006. The Value Chain of Foreign Aid: Development, Poverty Reduction, and Regional Conditions. Heidelberg: Physica-Verlag.

Smith, Kimberly, Talita Yamashiro Fordelone and Felix Zimmermann, 2010. Beyond the DAC: The Welcome Role of Other Providers of Development Co-operation. DCD Issues Brief.

Utz, Robert. 2010. Will countries that receive insufficient aid please stand up. CFP Research Program on the International Aid Architecture. IDA Resource Mobilization Department and Concessional Finance and Global Partnerships. 


\section{ENDNOTES}

'The grant ratio for the DAC countries as a whole in 2008 was $101.4 \%$. For Korea, the grant ratio in 2008 recorded $63.71 \%$

2 Such academic research has fed into policy. The International Development Agency (IDA) has adopted an allocation formula based on country performance rating, a composite index derived from a set of criteria from the World Bank's Country Policy and Institutional Assessment (CPIA) relating to economic management, structural policies, policies for social inclusion and equity and public sector management and institutions. Some bilateral donors such as the US (e.g., the Millenium Challenge Account), the UK, the Netherlands, Canada and Germany are known to have adopted such selective targeting of partner countries, using the CPIA as a guideline (Schabbel 2006, 10). See Nissanke (2010) for a critique of the "selectivity" approach, who points out that IDA puts too much weight on the country performance rating compared to recipient needs such as GNI per capita.

See Nunnenkamp. Thiele and Wilfer (2005), and Odedokun (2004) on details regarding the grant versus loan debate.

'It should be noted that aid to middle income countries is not necessarily always bad. Kanbur and Sumner (2011) point out that $72 \%$ of the world's poor belong to middle income countries. That is, aid should target "peor people" over "poor countries."

The Korean figure is based on projects approved for year 2009. The DAC average is for 2008 (EDCF 2010 ). 